\title{
Narrative review of male urethral sling for post-prostatectomy stress incontinence: sling type, patient selection, and clinical applications
}

\author{
Raevti Bole ${ }^{1}$, Kevin J. Hebert ${ }^{1}$, Harrison C. Gottlich ${ }^{2}$, Elizabeth Bearrick ${ }^{1}$, Tobias S. Kohler ${ }^{1}$, \\ Boyd R. Viers ${ }^{1}$ \\ ${ }^{1}$ Department of Urology, Mayo Clinic, Rochester, MN, USA; ${ }^{2}$ Mayo Clinic Alix School of Medicine, Rochester, MN, USA \\ Contributions: (I) Conception and design: BR Viers, TS Kohler; (II) Administrative support: None; (III) Provision of study materials or patients: \\ None; (IV) Collection and assembly of data: All authors; (V) Data analysis and interpretation: All authors; (VI) Manuscript writing: All authors; (VII) \\ Final approval of manuscript: All authors. \\ Correspondence to: Boyd R. Viers, MD. 200 First Street SW, Rochester, MN 55905, USA. Email: viers.boyd@mayo.edu.
}

\begin{abstract}
Male stress urinary incontinence (SUI) following prostate treatment is a devastating complaint for many patients. While the artificial urinary sphincter is the gold standard treatment for male SUI, the urethral sling is also popular due to ease of placement, lack of mechanical complexity, and absence of manual dexterity requirement. A literature review was performed of male urethral sling articles spanning the last zz20 years using the PubMed search engine. Clinical practice guidelines were also reviewed for comparison. Four categories of male urethral sling were evaluated: the transobturator AdVance and AdVance XP, the bone-anchored InVance, the quadratic Virtue, and the adjustable sling series. Well selected patients with mild to moderate urinary incontinence and no prior history of radiation experienced the highest success rates at long-term follow up. Patients with post-prostatectomy climacturia also reported improvement in leakage after sling. Concurrent penile prosthesis and sling techniques were reviewed, with favorable short-term outcomes demonstrated. Male urethral sling is a user-friendly surgical procedure with durable long-term outcomes in carefully selected men with mild stress urinary incontinence. Multiple sling types are available with varying degrees of efficacy and complication rates. Longer follow-up and larger cohort sizes are needed for treatment of newer indications such as climacturia as well as techniques involving dual placement of sling and penile prosthesis.
\end{abstract}

Keywords: Male urethral sling; climacturia; stress incontinence; Mini Jupette

Submitted Nov 27, 2020. Accepted for publication Jan 28, 2021.

doi: $10.21037 /$ tau-20-1459

View this article at: http://dx.doi.org/10.21037/tau-20-1459

\section{Introduction}

\section{Rationale/background}

Iatrogenic male stress urinary incontinence (SUI) is a distressing phenomenon occurring most commonly after treatment of the prostate gland $(1,2)$. Radiation therapy, open and robotic approaches to prostatectomy, as well as endoscopic procedures such as transurethral resection of the prostate (TURP) and holmium laser enucleation of the prostate (HoLEP) have all been implicated at post- procedure incidences ranging from $<0.5 \%$ to $21.3 \%$ at one year (3-6).

The surgical treatment of SUI has advanced considerably since the first artificial inflatable urethral cuff was invented in 1947 by Dr. Foley (7). The AMS 800 (AMS, Minnetonka, Minnesota) artificial urinary sphincter (AUS) is the most commonly used version of the gold standard treatment for male SUI today $(8,9)$. Regardless, surgical innovators have continued to search for less invasive and more durable alternatives to this device over the decades. 


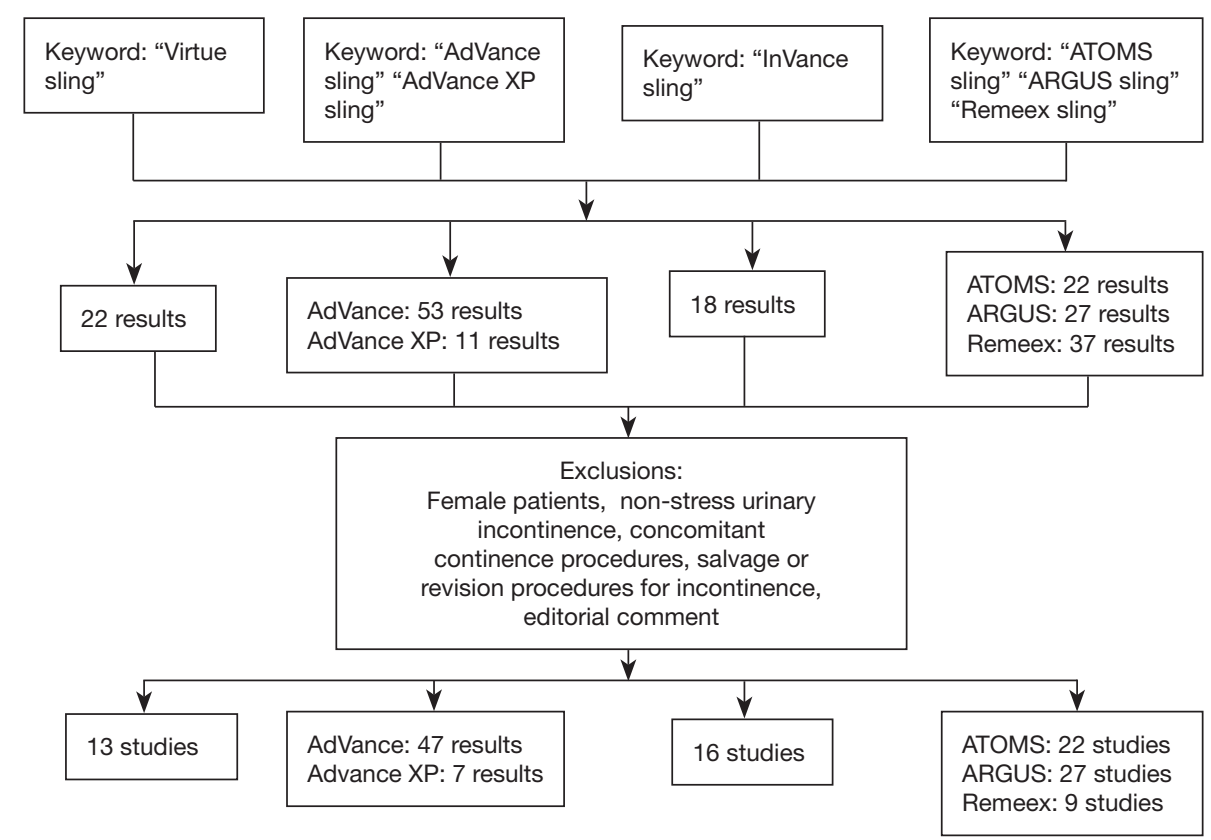

Figure 1 Flowchart of literature search.

The male urethral sling was first developed in the 1970s by American urologists John L. Berry and Joseph Kaufman who described placement of acrylic mesh ventral to the bulbar urethra (10). Early on, complications such as urinary fistulas and urethral erosions prevented the male sling from gaining widespread popularity but they developed a following in the 1990s as a management option for men with mild SUI, defined as $1-3$ pads per day (PPD) $(11,12)$. Kumar et al. reported in 2009 that when given a choice between the male sling versus the AUS, the majority of patients preferred the sling due to the lack of postoperative waiting period to achieve benefit, no need for device manipulation to urinate, and no risk of mechanical failure (13). National operative trends, as indicated by Medicare database analyses as well as case logs of practicing urologists, have shown increasing sling procedures being performed over time $(14,15)$. This being said, Liu et al. showed that AUS was still the most commonly performed male incontinence procedure during the period studied, especially for academically affiliated urologists (14).

\section{Objectives}

With the aging population and rise in treatment for age related conditions such as benign prostatic hyperplasia
(BPH) and prostate cancer, it is crucial for urologists to understand the unique benefits and limitations of each surgical treatment option for iatrogenic male SUI. The majority of incontinence procedures are done by a small percentage of surgeons with most urologists performing these cases infrequently (14). Therefore the current paper seeks to review the available literature on male urethral slings including a discussion of indications, patient selection, sling types, outcomes, and areas for future research. We present the following article in accordance with the Narrative Review Reporting Checklist (available at: http:// dx.doi.org/10.21037/tau-20-1459).

\section{Materials and methods}

\section{Data source}

A literature review to identify peer-reviewed, evidencebased articles published in the last 20 years (2000 to present) was conducted using the search engine PubMed (Figure 1). A variety of key words were utilized and the references of each identified article were thoroughly reviewed. Furthermore, clinical practice guidelines from the following societies were reviewed: American Urological Association (AUA), Canadian Urological Association (CAU), and European Association of Urology (EAU). 


\section{Article selection}

Preference in article evaluation, in descending order, was as follows: randomized control trials, society guidelines, multicenter series, single institution/single surgeon series and review articles. Exclusion criteria included articles reporting: female patients, concomitant procedures known to affect urinary continence (injection of bulking agents, bladder neck repair etc) and urethral sling as a secondary or salvage procedure following failed primary incontinence procedure.

\section{Outcomes of interest}

The primary outcome evaluated was urinary continence. As definitions, evaluations or measuring systems for the degree of pre and post intervention urinary incontinence varied throughout the literature, all data reported herein utilizes the definitions specified in each individual article. Secondary outcomes evaluated, when reported, include: patient satisfaction, comparison of pre and post intervention standardized questionnaires, surgical complications, failure rates, re-intervention rates, erosion/explanation rates and median follow-up time.

\section{Narrative}

Four categories of male urethral sling are described: the transobturator sling (AdVance and Advance XP), the boneanchored sling (InVance), the quadratic sling (Virtue) and the adjustable sling (ATOMS, ARGUS and Remeex). The primary outcome of continence was most commonly assessed using number of PPD, though some studies also used pad weights. Table 1 provides an overview of the outcomes for slings which are commercially available in the Unites States; namely the Advance XP and Virtue slings. Articles with at least 20 patients and 6 months of follow up were chosen for representation in the table.

\section{The AdVance sling}

The Advance (Boston Scientific, formerly AMS, Minnetonka, MN) is a transobturator sling that works by repositioning the bulbar urethra proximally and supporting the distal membranous urethra without causing obstruction (27). Of note, the AdVance has now been completely replaced by the AdVance XP and is no longer available to purchase.
The objective success rate is defined in most studies by the 24-hour pad test as 0-1 PPD. This is as high as $73 \%$ with the Advance Sling reported by Soljanik et al. in a study of 189 patients at mean 20.8 months of follow up (28). Using more stringent criteria of 0 PPD, Cornu et al. reported a $63 \%$ success rate in 136 patients at 21 months (29). Finally, using the most stringent objective definition of less than 2 grams of urine in 24 hours, Cornel et al. reported success in only $9 \%$ of 36 patients at 12 months (30).

Predictors of worse postoperative continence were history of prostate radiation and severe baseline incontinence (31-35). Chung et al. noted that it is important to ensure a smooth extubation from anesthesia to avoid loosening of the sling with coughing (36). The overall complication rate was $12.3 \%$ in a systematic review by Crivellaro et al. (37). The most commonly reported complication was temporary urinary retention in $5 \%$ to $21.3 \%$ of patients, though Cornu et al. reported no retention in their large series and reports of permanent retention were rare (38-40). Bauer et al. also noted that severe complications were uncommon, as was explantation of the sling which occurred in $1 \%$ of patients (41).

\section{The AdVance XP sling}

The AdVance XP (Boston Scientific, formerly AMS, Minnetonka, MN) is a transobturator sling similar to the AdVance with the addition of Chevron tissue-anchoring mechanism to prevent sling migration, 2 absorbable sutures with knots and strengthen heat-sealed mesh edges, a Tyvek liner within plastic sheath, and longer mesh arms for easier use in larger patients (16). The AdVance XP has now entirely replaced the AdVance.

Bauer et al. reported that $64.9 \%$ of 114 patients were cured at 3 months using the AdVance XP sling, while $66 \%$ of 40 patients remained cured at 36 months (17). High long-term positive outcome rates were also noted in a study of 115 patients, where $71.7 \%$ of the patients were cured, while $15.0 \%$ had improved symptoms (18). In contrast, another study of 41 patients reports only $46.3 \%$ and $29.3 \%$ of patients were respectively reported as cured and improved at 36 months (42).

Significant differences in outcomes or complication rates were not noted in papers directly comparing Advance and Advance XP slings. Mean operative time, outcomes, and most complication rates were comparable at a mean follow-up time of 34.7 months among 79 AdVanceXP and 47 AdVance patients in one study (43). The only significant 
Table 1 Comparison of success rates in commercially available male urethral slings in the United States for treatment of stress urinary incontinence

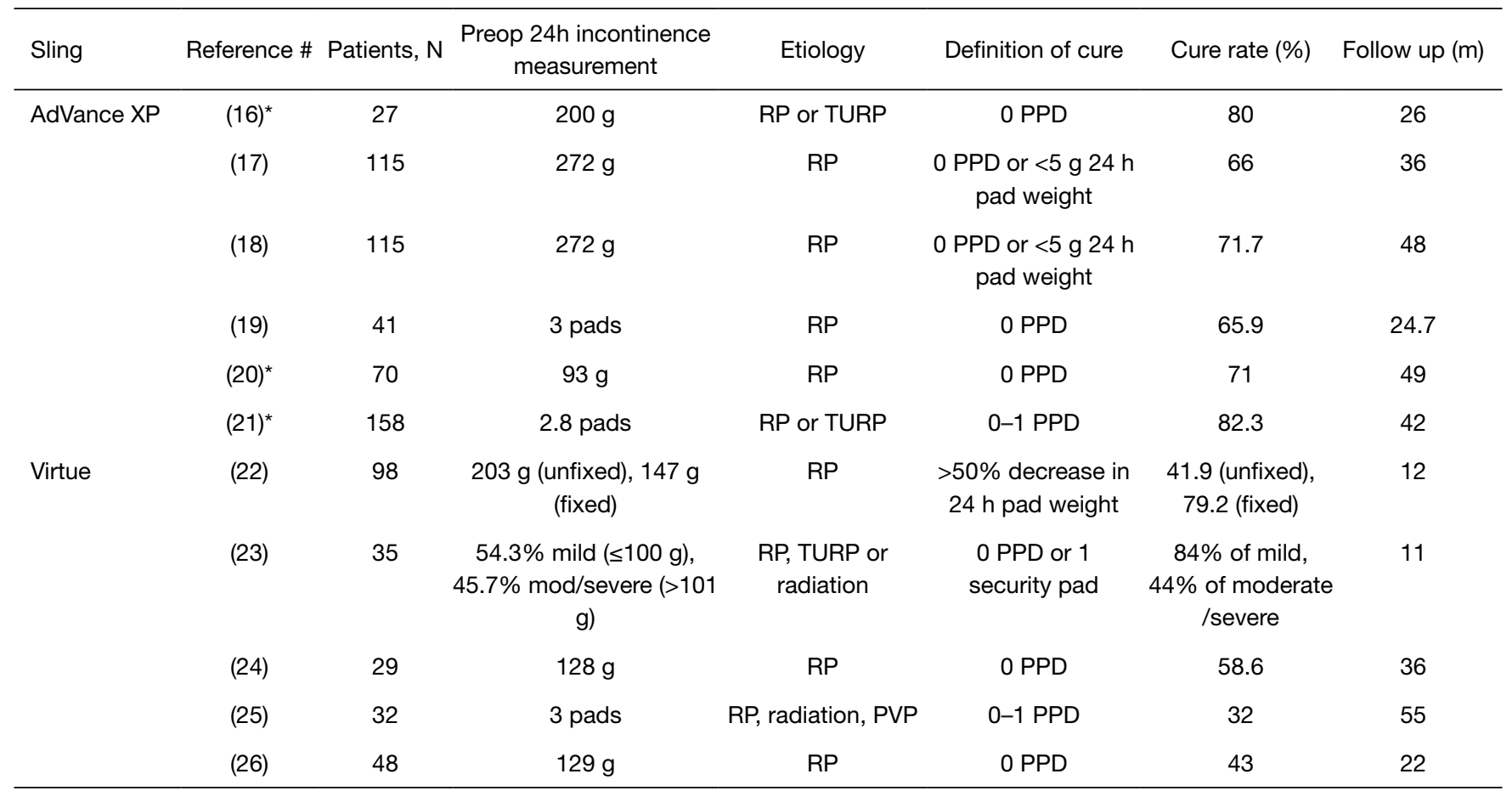

*, no statistical breakdown between AdVance and AdVance XP continence outcomes. RP, radical prostatectomy; TURP, transurethral resection of the prostate; PVP, photovaporization of the prostate.

difference found was in urinary retention, with $3.7 \%$ and $10.3 \%$ of patients in the AdVance and AdvanceXP groups respectively affected (43). The lack of significant differences between the slings was noted in other papers $(19,44)$. Collado et al. reported no significant difference between the slings but noted that preoperative 24 hour pad weight was significantly related to postoperative continence outcome (20).

\section{The InVance Sling}

The InVance Sling (American Medical Systems, Minnetonka, MN, USA) is bone-anchored sling attached to the ischiopubic rami with a silicon-coater polyester sling positioned under the bulbar urethra (45). Note that due to complication rate and risk of bone infection the InVance sling is no longer on the market, therefore it is mentioned for historical context only.

A study of 106 patients, $75.5 \%$ and $5.7 \%$ of patients reported being dry or improved at three months, respectively (46). The rate of little or not improved at 3 months was $18.8 \%$ and increased to $24.5 \%$ at one year (46).
Spie et al. also recorded 106 cases stratified into previous radiotherapy $(\mathrm{n}=24)$ and a non-radiotherapy control group ( $\mathrm{n}=82$ ) showing that while 3 month results were similar, at 12 months continence declined in the radiotherapy group to $53.6 \%$ and remained $62.5 \%$ for the control group (47).

When examining predictors of success, Carmel et al. did not find significant differences in outcomes between mild (preoperative 2-3 PPD) and severe (preoperative $>3$ PPD) stress urinary incontinence groups (48). Other studies have found deteriorating success rates correlating with more severe preoperative conditions $(46,49,50)$. Three preoperative parameters were noted by Lanoe et al. to be significantly associated with sling failure: severe urinary incontinence, urodynamic detrusor instability, and incontinence due to biotherapy, including external radiation (51). Regarding complications, explanting the sling due to bone infection was needed in as many as $17 \%$ of cases (51). Other studies noted a need to reposition the sling, transient perineal and scrotal pain or numbness, de novo urinary irritative disorders and acute urinary retention requiring catheterization (48). An increased rate of 
complications was correlated with increased operation time and patients' age $(46,49,51,52)$.

One study compared participants stratified into AdVance and InVance Sling groups, finding that $79.1 \%$ in the Advance group versus $77.4 \%$ in the InVance group reported being cured ( 0 PPD) although almost $30 \%$ of the AdVance group and $16 \%$ of the InVance cures deteriorated at 5 year follow up (53). The InVance group had a higher percentage of complications of $22.2 \%$ compared to $16.8 \%$ in the Advance group (53).

\section{The Virtue Quadratic Sling}

The Virtue (Coloplast Humlebaek, Denmark) quadratic sling is a transobturator sling with a 4-armed large pore mesh providing proximal urethral relocation using a TO component together with a prepubic component providing perineal urethral compression (22).

In a study of 29 patients using a criterion of success of patients being dry (0 PPD or 1 PPD for precaution), $\geq 1 \mathrm{PPD}$, or an at least $50 \%$ decrease in pad usage, a success rate of $83 \%$ was reported at a mean follow-up of 11 months (23). Nineteen $(54.3 \%)$ and $16(45.7 \%)$ patients in this study were characterized preoperatively with mild ( $\leq 2$ protections and/or $<100 \mathrm{~mL} / 24 \mathrm{~h}$ ) or moderate (3-4 protections and/ or $101-200 \mathrm{~mL} / 24 \mathrm{~h}$ ) /severe ( $>4$ protections and/or > $200 \mathrm{~mL} / 24 \mathrm{~h}$ ) incontinence, respectively (23). Importantly, the high success rate differed by preoperative conditions, with the mild group having an $84 \%$ success rate and the severe group with a $43 \%$ success rate (23).

A second study found $100 \%$ of patients $(n=29)$ used at most $1 \mathrm{PPD}$ and were satisfied with the procedure at 12 months follow-up (24). In contrast to these two studies' positive results, in a long-term study (median followup of 55 months) with failure defined as no change in postoperative pad use, failure to reduce leakage below 2 PPD, need for an artificial genitourinary sphincter, and/ or need for sling explant, there was a reported failure rate of $68 \%(\mathrm{n}=21)(25)$. In this study, only $32 \%$ of patients $(\mathrm{n}=10)$ were considered successful at the end of the longer followup period (25).

Reported surgery complications included scrotal pain, acute urinary retention and infections requiring explanting of the sling (24-26). Previous radiotherapy and more severe preoperative incontinence were associated with higher failure rates (23). McCall et al. and Hogewoning et al. both cautioned that longer monitoring and reporting of Virtue Quadratic outcomes is needed $(25,54)$.

\section{The Adjustable Sling}

Three popular adjustable slings are the Argus classic and ArgusT (Promedon, Argentina), ATOMS (A.M.I., Austria), and Remeex (Neomedic International, Spain). These models provide pressure on the bulbar and membranous urethra to improve continence (55). At the time of this article, these slings are not yet approved by the United States Food \& Drug Administration for use in the United States.

In the largest study of 215 ATOMS patients, Angulo et al. achieved a success rate of $80.5 \%(96.2 \%$ and $75.3 \%$ in the mild and moderate-severe preoperative group, respectively) (56). They reported that 121 patients (56.3\%) did not use any pads and 52 patients $(24.2 \%)$ used a security pad (less than $10 \mathrm{~mL}$ of urine loss) (56). At mean 24.3 months follow-up, the dry rate decreased to $73 \%$, while $3.25 \%(\mathrm{n}=7)$ patients required the device's explantation (56). Worse preoperative incontinence and radiotherapy were found to be predictors of decreased success (56). Doiron et al. also reported a high continence rate of $80.0 \%$ with improvement in $87.8 \%$ cases in a 60 -patient study at a median follow-up of 9.0 months (57). Seventy percent of these patients underwent a mean of 2.4 (SD 2.7) adjustments (57).

In looking at the Argus sling, Cotugno et al. reported a short-term study at 3 months post-operation that $70 \%$ (21 patients) reached total continence defined as using less than one PPD (58). The remaining 30\% (9 patients) were noted as having a clinically significant improvement (58). Looking at differences in outcome due to preoperative conditions, Bochove-Overgaauw et al. reported differences of $92 \%$ (12 of 13), 67\% (29 of 43), and 67\% (26 of 39) in the mild, moderate, and severe incontinence group (59). A complicating factor for the Argus' high success rate is the reported decline in continence over time. In a study of 74 Argus classic patients and 32 ArgusT patients, Loertzer et al. reported a long-term dry rate at a median follow-up of 44.0 months of only $33.0 \%$ and $11.8 \%$, respectively (60). They did not confirm the ArgusT model as an independent predictor of procedure success but did note that inguinal pain and explanation rates were higher for the Argus T sling (43). When looking at complications, Cerniauskiene et al. reported that $54 \%(n=22)$ experienced 31 complications, including intra-operative bladder perforation and postoperative like acute urinary retention and infection (61). Kretschmer et al. compared complication rates in 127 adjustable sling patients (95 Argus classic and 32 Argus T) to 155 artificial 
Table 2 Factors associated with improved male urethral sling outcomes

Patient factors to consider
$\leq 2$ pads per day
MSIGS score of $0-2$
No history of radiation or prior urethral surgery
Pad weight $<200 \mathrm{~g} /$ day
Voluntary coaptation of external sphincter
Perineal repositioning test
Adequate detrusor contractility
Lack of detrusor overactivity
Low post-void residual

urinary sphincter (AUS) patients (62). The adjustable slings were noted to have significantly increased intraoperative complication rates $(15.9 \%$ to $4.2 \%, \mathrm{P}=0.003)$; however, explantation rates were significantly lower for the adjustable slings than the AUS devices (9.2\% vs. $21.5 \%, \mathrm{P}=0020)(62)$.

The last major adjustable sling type is the Remeex device. Sousa-Escandon et al. reported in a study of 55 patients using the Remeex sling that, after additional adjustments at a mean follow-up of 32 months, that $45 \%(n=25)$ of patients used no pads, $15 \%(\mathrm{n}=8)$ used a security pad, 19.6\% $(\mathrm{n}=10)$ had improvement in symptoms, and $15.7 \%(\mathrm{n}=8)$ remained unchanged (63). They reported urethral erosion in $2(4 \%)$ cases and $5(9 \%)$ cases of intraoperative bladder perforations (63). A more recent study reported slightly worse outcome rates in 25 patients of whom $36 \%(n=9)$ patients were cured but $28 \%(n=7)$ did not improve at a mean follow up of 31 months (64).

\section{Summary}

\section{Work-up/Identification of the Ideal Sling Candidate}

Multiple studies have attempted to characterize the ideal sling candidate with the highest chance of post-treatment success. Morey et al. developed a Male Stress Incontinence Grading Scale (MSIGS) in 2016 to assess the severity of post-prostatectomy incontinence (65). Per the MSIGS protocol, patients wait at least 60 minutes after their last void, and then forcefully cough 4 times while in the standing position. The degree of incontinence is then assessed by 2 examiners as follows: Grade 0 leakage not demonstrated on exam, Grade 1 delayed drops, Grade 2 early drops,
Grade 3 delayed stream, and Grade 4 is early stream. In a review of AdVance sling placement spanning 9 years, Viers et al. found that patients without radiation history, MSIGS $0-2$, and preoperative use of 2 or less PPD enjoyed an $81 \%$ success rate, defined as $1 \mathrm{PPD}$ or less (66). Shakir et al. then used the MSIGS to rapidly evaluate first-time male sling candidates with history and clinical exam alone, finding that the addition of MSIGS to a predictive nomogram increased the prognostic value significantly (67).

Sturm et al. also explored the concept of an "ideal" sling candidate in a retrospective study, defining "ideal" as those patients with mild to moderate incontinence, good sphincter control and detrusor function, no radiation history and low post-void residual (68). Cure as defined by 0 PPD was achieved by $50 \%$ of ideal patients versus only $22 \%$ of nonideal patients (68). Other studies have also found degree of preoperative incontinence to be highly predictive of sling success $(16,21,69)$. One should be aware that the definition of incontinence has been debated by many. While Nitti et al. found excellent concordance in their prospective analysis of patient perception of pad use compared to actual number and weight of pads used, other studies found that reported PPD did not correlate well with 24 hour pad weight (70-72). Surgeons may therefore consider the standing cough test, which does correlate strongly with 24 hour pad weight and may be a more useful metric for patient selection (73).

To this end, national and international guidelines propose that male slings be used only for mild to moderate incontinence, as men with severe incontinence would have greater benefit from an AUS $(74,75)$. The guidelines also advise that a history of radiation, or prior surgery for urethral stricture are predictors of negative outcomes (75). This is likely secondary to fixation of the urethra which limits proximal relocation as well as healing.

It is important for surgeons to be as objective as possible about patient selection for male urethral sling and avoid being overly swayed by patient preference or personal comfort with sling technique. In fact, $25 \%$ of patients would even choose the sling against surgeon recommendations due to their motivation to avoid a mechanical device (13). Table 2 highlights preoperative patient factors that may streamline the selection of candidates who are most likely to benefit from male urethral sling. We recommend office cystoscopy prior to surgical intervention for incontinence to rule out urethral stricture or bladder pathology, and characterize urethral health and degree of voluntary membranous urethral coaptation (68). The perineal repositioning 
test can also be performed which Bauer et al. found was significantly correlated with postoperative cure rate in a prospective study (76). This reflects the ability of the male sling to mechanically reposition the proximal bulbar urethra and reinforce a functioning external urinary sphincter complex-both critical components to sling success.

Urodynamic evaluation is of variable importance in the evaluation of male stress urinary incontinence unless the diagnosis is in question. Patients with underactive bladders are thought to be best served by AUS, as adequate detrusor contractility is needed to urinate against the compressive force of a sling (77). However as Han et al. have shown, patients with underactive detrusor contractility can still undergo sling placement without significant increases in urinary retention rate (78). Theoretically, patients who Valsalva void may also be at higher risk of loosening the sling postoperatively and may need to be counseled accordingly (36). On the other end of the spectrum, overactive bladder can develop in almost half of post-prostatectomy patients and may need to be treated; however, it alone does not preclude men from undergoing sling for stress incontinence (79).

With regards to timing of anti-incontinence procedures, studies suggest that conservative management should be used for the first year after surgery to allow for patients to recover to their fullest extent (80). Matsushita et al. found that membranous urethral length on preoperative prostate MRI was predictive of continence recovery at 6 and 12 months, which is helpful for patient counseling and avoidance of overtreatment.

\section{Sling for stress incontinence}

While no one sling type is currently recommended over another by the incontinence guidelines, certain situations may favor a particular approach. For example, in patients with detrusor underactivity, the transobturator sling's noncompressive mechanism of action may result in lower rates of postoperative retention (80).

The quadratic sling may improve, but not cure, more severe levels post-prostatectomy leakage using a novel fixation technique by Comiter et al. $(22,81)$. Their study design incorporated intraoperative measurement of retrograde leak point pressure of $60 \mathrm{cmH}_{2} \mathrm{O}$ to guide tensioning of the sling's transobturator and prepubic arms (22). Eighty percent of patients reported $>50 \%$ decrease in 24 hour pad weight with no difference seen based on preoperative incontinence level. The transobturator and bone-anchored slings, by comparison, have not been modified for use in men with severe urinary leakage (74).

In the event there is persistence or recurrence of SUI after quadratic sling placement, an artificial urinary sphincter can be effectively placed by division of the mesh component and exposure of underlying bulbar urethra (82). Others have reported revising the quadratic sling alone through a series of imbricating tensioning sutures with good results (81). In general, sling success is highly dependent upon patient selectivity. As such, patients with moderate to severe incontinence, history of radiation, or requiring a salvage procedure after failed urethral sling, implantation of an AUS is preferable.

\section{Sling for climacturia}

Climacturia is a bothersome condition in which patients report incontinence with orgasm. While previously underreported, it is now thought to be prevalent in $23 \%$ to $40 \%$ of men post radical prostatectomy $(83,84)$. A retrospective review by Nolan et al. found that in men with general stress incontinence plus climacturia, AdVance slings improved both subjective frequency of climacturia as well as associated bother (85). Christine and Bella placed AdVance slings in 46 men with climacturia, all of whom reported resolution and $86 \%$ of whom also reported complete resolution of stress incontinence (86). Jain et al. evaluated 11 men who underwent surgery for SUI and climacturia; $75 \%$ of those who underwent AUS and $57 \%$ of those who underwent sling reported marked improvement in climacturia.

\section{Erectile dysfunction with concurrent treatment of incontinence (Mini Fupette)}

For post radical prostatectomy patients with both erectile dysfunction and mild stress urinary incontinence, R. Andrianne described the placement of a "mini Jupette" mid urethral sling-French for mini-skirt—at the same time as an inflatable penile prosthesis (IPP) (87). A polypropylene graft is sutured to the medial aspect of the corporotomies such that when the IPP cylinders inflate, the sling compresses the urethra. Yafi et al. performed a prospective multicenter investigation of this technique, finding that almost $80 \%$ of patients experienced resolution of climacturia with a postoperative complication rate of $7.9 \%$, no higher than for IPP placement alone (88). Tutoplast 

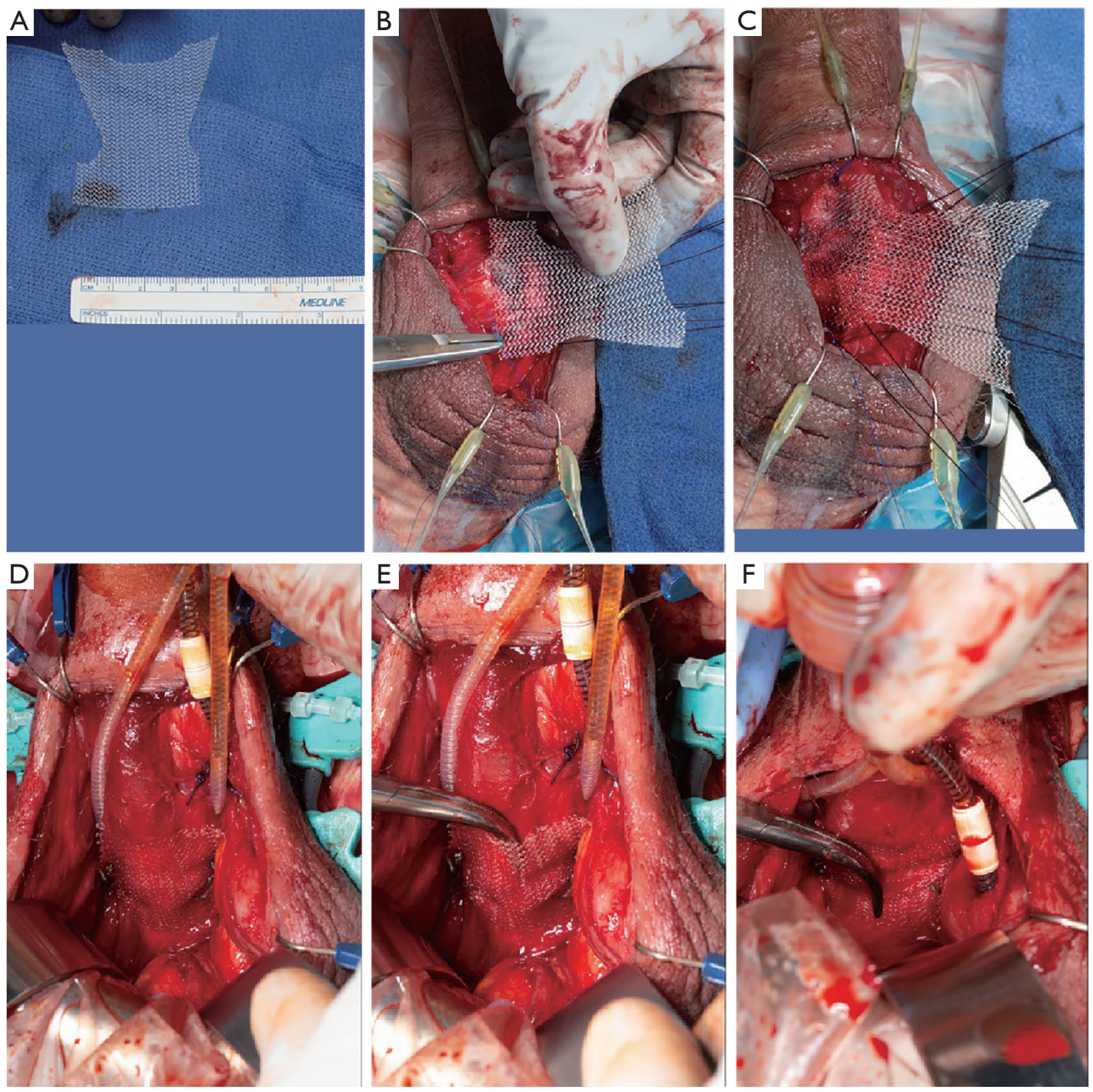

Figure 2 The Mayo Clinic modified Mini Jupette technique. Ethibond stay sutures are preplaced in four quadrants, directly inferior to the IPP corporotomy sites. IPP is placed in standard fashion and corporotomies are closed. (A) Four limbs are cut off a Coloplast Virtue Quadratic sling. (B) Preplaced Ethibond sutures being passed through mesh. (C) Ethibond sutures passed through one side of sling. (D) Mini-Jupette mesh tied down in place with IPP deflated. (E) Right angle can be accommodated when IPP deflated. (F) Right angle cannot be accommodated with maximal IPP inflation.

bovine pericardium and autologous fascia have also been used as alternate graft materials with success rates over $80 \%(89,90)$.

Since the original technique, other surgeons have described modifications such as the Mayo technique by Dr. Tobias Kohler in which a Virtue sling with the limbs cut off is affixed over the proximal bulbar urethra, such that a right angle can slide under the sling when the IPP is deflated
(Figure $2 A, B, C, D, E, F)$ (89). Valenzuela et al. similarly used Virtue sling mesh in 36 patients, observing resolution of climacturia in $93 \%$ (91).

Dual implantation of IPP and sling is not overly time consuming with a total procedural time equivalent to each separate procedure; and one study showed cost savings of approximately $\$ 9,000$ (92). Infection rate has been reported at $1.2 \%$ by some authors, which is comparable with IPP 
placement alone (93). Concomitant implantation of AUS and IPP has also been described, with placement of both reservoirs within either the space of Retzius or a high submuscular tunnel (94). However, as evidenced by Morey et al., the combination of IPP and AUS may be associated with greater risk of urethral erosion due to compression of the urethral cuff by the rigid rear-tip extenders (95). In this population of men, selective use of a transobturator or quadratic sling in combination with IPP may serve as a viable alternative to address male SUI and potentially reduce the risk of long-term urethral injury.

\section{Limitations}

There are several limitations to this review worthy of discussion. First, this review article is limited by the quality of currently published material on this topic. Second, aggregate statistical analysis or direct comparison between articles is challenged by the lack of standardized reporting metrics for pre and post intervention incontinence. Within these limitations, this is one of the most comprehensive reviews on the male urethral sling spanning two decades of published literature. Studies with longer follow-up to address sling durability and larger cohorts to evaluate efficacy of newer techniques such as the Mini-Jupette are needed.

\section{Conclusions}

While post-prostatectomy SUI is the primary indication for male urethral sling, bothersome climacturia is also improved. The ideal sling candidate has mild to moderate incontinence, no history of radiation, and no evidence of bladder outlet obstruction. In this large, 20-year contemporary review of male urethral sling, we explore the types of male slings currently available, continence outcomes, and complication rates as reported by highvolume urologists. Future studies with larger patient cohorts and long-term outcomes are needed for promising new techniques such as concomitant placement of sling and penile prosthesis.

\section{Acknowledgments}

Funding: None.

\section{Footnote}

Provenance and Peer Review: This article was commissioned by the editorial office, Translational Andrology and Urology for the series "Controversies and Considerations of Penile Surgery". The article has undergone external peer review.

Reporting Checklist: The authors have completed the Narrative Review Reporting Checklist. Available at: http:// dx.doi.org/10.21037/tau-20-1459

Conflicts of Interest: The authors have completed the ICMJE uniform disclosure form (available at http://dx.doi. org/10.21037/tau-20-1459). The series "Controversies and Considerations of Penile Surgery" was commissioned by the editorial office without any funding or sponsorship. TSK served as the unpaid Guest Editor of the series and serves as an unpaid Associate Editor-in-Chief of Translational Andrology and Urology from Jan 2020 to Dec 2021. The authors have no other conflicts of interest to declare.

Ethical Statement: The authors are accountable for all aspects of the work in ensuring that questions related to the accuracy or integrity of any part of the work are appropriately investigated and resolved.

Open Access Statement: This is an Open Access article distributed in accordance with the Creative Commons Attribution-NonCommercial-NoDerivs 4.0 International License (CC BY-NC-ND 4.0), which permits the noncommercial replication and distribution of the article with the strict proviso that no changes or edits are made and the original work is properly cited (including links to both the formal publication through the relevant DOI and the license). See: https://creativecommons.org/licenses/by-nc-nd/4.0/.

\section{References}

1. Penson DF, McLerran D, Feng Z, et al. 5-year urinary and sexual outcomes after radical prostatectomy: results from the prostate cancer outcomes study. J Urol 2005;173:1701-5.

2. Liss MA, Osann K, Canvasser N, et al. Continence definition after radical prostatectomy using urinary quality of life: evaluation of patient reported validated questionnaires. J Urol 2010;183:1464-8.

3. Liu M, Pickles T, Berthelet E, et al. Urinary incontinence in prostate cancer patients treated with external beam radiotherapy. Radiother Oncol 2005;74:197-201.

4. Rassweiler J, Teber D, Kuntz R, et al. Complications of transurethral resection of the prostate (TURP)--incidence, 
management, and prevention. Eur Urol 2006;50:969-79; discussion 980.

5. Fallara G, Capogrosso P, Schifano N, et al. Ten-year Follow-up Results After Holmium Laser Enucleation of the Prostate. Eur Urol Focus 2020;S24054569(20)30147-4.

6. Haglind E, Carlsson S, Stranne J, et al. Urinary Incontinence and Erectile Dysfunction After Robotic Versus Open Radical Prostatectomy: A Prospective, Controlled, Nonrandomised Trial. Eur Urol 2015;68:216-25.

7. Foley FE. An artificial sphincter; a new device and operation for control of enuresis and urinary incontinence. J Urol 1947;58:250-9.

8. Kim SP, Sarmast Z, Daignault S, et al. Long-term durability and functional outcomes among patients with artificial urinary sphincters: a 10-year retrospective review from the University of Michigan. J Urol 2008;179:1912-6.

9. Lai HH, Hsu EI, Teh BS, et al. 13 years of experience with artificial urinary sphincter implantation at Baylor College of Medicine. J Urol 2007;177:1021-5.

10. Chong JT, Simma-Chiang V. A historical perspective and evolution of the treatment of male urinary incontinence. Neurourol Urodyn 2018;37:1169-75.

11. Osman NI. Slings in the management of male stress urinary incontinence. Curr Opin Urol 2013;23:528-35.

12. Trost L, Elliott DS. Male stress urinary incontinence: a review of surgical treatment options and outcomes. Adv Urol 2012;2012:287489.

13. Kumar A, Litt ER, Ballert KN, et al. Artificial urinary sphincter versus male sling for post-prostatectomy incontinence--what do patients choose? J Urol 2009;181:1231-5.

14. Liu JS, Hofer MD, Milose J, et al. Male Sling and Artificial Urethral Sphincter for Male Stress Urinary Incontinence Among Certifying American Urologists. Urology 2016;87:95-9.

15. Chughtai B, Sedrakyan A, Isaacs AJ, et al. National study of utilization of male incontinence procedures. Neurourol Urodyn 2016;35:74-80.

16. Collado Serra A, Resel Folkersma L, Dominguez-Escrig $\mathrm{JL}$, et al. Advance/Advance XP transobturator male slings: preoperative degree of incontinence as predictor of surgical outcome. Urology 2013;81:1034-9.

17. Bauer RM, Grabbert MT, Klehr B, et al. 36-month data for the advance $\mathrm{XP}((\mathrm{R}))$ male sling: results of a prospective multicentre study. BJU Int 2017;119:626-30.

18. Grabbert M, Mumm JN, Klehr B, et al. Extended follow- up of the advance XP male sling in the treatment of male urinary stress incontinence after 48 months: Results of a prospective and multicenter study. Neurourol Urodyn 2019;38:1973-8.

19. Bauer RM, Kretschmer A, Stief CG, et al. Advance and advance XP slings for the treatment of post-prostatectomy incontinence. World J Urol 2015;33:145-50.

20. Collado A, Dominguez-Escrig J, Ortiz Rodriguez IM, et al. Functional follow-up after Advance((R)) and Advance $\mathrm{XP}((\mathrm{R}))$ male sling surgery: assessment of predictive factors. World J Urol 2019;37:195-200.

21. Zemp L, Tong S, Hoy N, et al. Preoperative pad usage is independently associated with failure of non-adjustable male trans-obturator slings in otherwise well-selected patients. Can Urol Assoc J 2019;13:120-4.

22. Comiter CV, Rhee EY, Tu LM, et al. The virtue sling--a new quadratic sling for postprostatectomy incontinence-results of a multinational clinical trial. Urology 2014;84:433-8.

23. Abdullah A, Machkour F, Bouchet E, et al. Efficacy of the VIRTUE male quadratic sling in the treatment of stress urinary incontinence: A retrospective study. Prog Urol 2019;29:490-5.

24. Ferro M, Bottero D, D'Elia C, et al. Virtue male sling for post-prostatectomy stress incontinence: a prospective evaluation and mid-term outcomes. BJU Int 2017;119:482-8.

25. McCall AN, Rivera ME, Elliott DS. Long-term Followup of the Virtue Quadratic Male Sling. Urology 2016;93:213-6.

26. Sourial MW, Richard PO, Morisset J, et al. Retrograde leak point pressure measurement improves outcomes of the Virtue male sling for postprostatectomy incontinence. Can Urol Assoc J 2017;11:E271-6.

27. Rehder P, Staudacher NM, Schachtner J, et al. Hypothesis That Urethral Bulb (Corpus Spongiosum) Plays an Active Role in Male Urinary Continence. Adv Urol 2016;2016:6054730.

28. Soljanik I, Gozzi C, Becker AJ, et al. Risk factors of treatment failure after retrourethral transobturator male sling. World J Urol 2012;30:201-6.

29. Cornu JN, Sebe P, Ciofu C, et al. Mid-term evaluation of the transobturator male sling for post-prostatectomy incontinence: focus on prognostic factors. BJU Int 2011;108:236-40.

30. Cornel EB, Elzevier HW, Putter H. Can advance transobturator sling suspension cure male urinary postoperative stress incontinence? J Urol 
2010;183:1459-63.

31. Papachristos A, Mann S, Talbot K, et al. Advance male urethral sling: medium-term results in an Australian cohort. ANZ J Surg 2018;88:E178-82.

32. Zuckerman JM, Tisdale B, McCammon K. Advance male sling in irradiated patients with stress urinary incontinence. Can J Urol 2011;18:6013-7.

33. Siegler N, Droupy S, Costa P. Sub-urethral sling Advance((R)) midterm results: patient selection and predictors of success. Prog Urol 2013;23:986-93.

34. Štimac G, Spajic B, Popovic A, et al. Transobturator Advance(R) Sling Suspension for the Treatment of Postprostatectomy Stress Urinary Incontinence. Acta Clin Croat 2018;57:77-84.

35. Habashy D, Losco G, Tse V, et al. Mid-term outcomes of a male retro-urethral, transobturator synthetic sling for treatment of post-prostatectomy incontinence: Impact of radiotherapy and storage dysfunction. Neurourol Urodyn 2017;36:1147-50.

36. Chung ASJ, Suarez OA, McCammon KA. Advance male sling. Transl Androl Urol 2017;6:674-81.

37. Crivellaro S, Morlacco A, Bodo G, et al. Systematic review of surgical treatment of post radical prostatectomy stress urinary incontinence. Neurourol Urodyn 2016;35:875-81.

38. Cornu JN, Sebe P, Ciofu C, et al. The Advance transobturator male sling for postprostatectomy incontinence: clinical results of a prospective evaluation after a minimum follow-up of 6 months. Eur Urol 2009;56:923-7.

39. Mueller J, Schrader AJ, Schnoeller T, et al. The retrourethral transobturator sling suspension in the treatment of male urinary stress incontinence: results of a single institution experience. ISRN Urol 2012;2012:304205.

40. Rehder P, Haab F, Cornu JN, et al. Treatment of postprostatectomy male urinary incontinence with the transobturator retroluminal repositioning sling suspension: 3-year follow-up. Eur Urol 2012;62:140-5.

41. Bauer RM, Mayer ME, May F, et al. Complications of the Advance transobturator male sling in the treatment of male stress urinary incontinence. Urology 2010;75:1494-8.

42. Kretschmer A, Buchner A, Leitl B, et al. Long-term Outcome of the Retrourethral Transobturator Male Sling After Transurethral Resection of the Prostate. Int Neurourol J 2016;20:335-41.

43. Hüsch T, Kretschmer A, Thomsen F, et al. The advance and advance XP male sling in urinary incontinence: is there a difference? World J Urol 2018;36:1657-62.
44. Cornu JN, Batista Da Costa J, Henry N, et al. Comparative study of AdVance and AdVanceXP male slings in a tertiary reference center. Eur Urol 2014;65:502-4.

45. Suzuki Y, Saito Y, Kondo Y. Bone-anchored sling created with the InVance system for the treatment of incontinence after radical prostatectomy: initial experience in Japan. J Nippon Med Sch 2012;79:143-6.

46. Claudon P, Spie R, Bats M, et al. Male stress urinary incontinence: medium-term results of treatment by sub-urethral bone anchored sling InVance. Prog Urol 2011;21:625-30.

47. Spie R, Claudon P, Raynal G, et al. Radiotherapy influence, about results of the InVance((R)) male sling in men with stress urinary incontinence. Prog Urol 2011;21:549-53.

48. Carmel M, Hage B, Hanna S, et al. Long-term efficacy of the bone-anchored male sling for moderate and severe stress urinary incontinence. BJU Int 2010;106:1012-6.

49. Collado A, Gomez-Ferrer A, Rubio-Briones J, et al. Which patients with stress urinary incontinence after radical prostatectomy benefit from the indication of an Invance? Archivos espanoles de urologia 2009;62:851-9.

50. Athanasopoulos A, Konstantinopoulos A, McGuire E. Efficacy of the InVance male sling in treating stress urinary incontinence: a three-year experience from a single centre. Urol Int 2010;85:436-42.

51. Lanoe M, Saussine C, Mouracade P, et al. Male stress urinary incontinence by InVance bone anchored suburethral sling: Predictive factors of treatment failure: Multicentric study by the CTMH-AFU. Prog Urol 2009;19:839-44.

52. Guimarães M, Oliveira R, Pinto R, et al. Intermediateterm results, up to 4 years, of a bone-anchored male perineal sling for treating male stress urinary incontinence after prostate surgery. BJU Int 2009;103:500-4.

53. Collado-Serra A, Dominguez-Escrig J, Ramirez-Backhaus $M$, et al. Long-term functional outcome and complications of male suburethral slings in the management of postprostatectomy incontinence: A prospective fiveyear follow-up study. Archivos espanoles de urologia 2019;72:381-8.

54. Hogewoning CRC, Meij LAM, Pelger RCM, et al. Sling Surgery for the Treatment of Urinary Incontinence After Transurethral Resection of the Prostate: New Data on the Virtue Male Sling and an Evaluation of Literature. Urology 2017;100:187-92.

55. Meisterhofer K, Herzog S, Strini KA, et al. Male Slings for Postprostatectomy Incontinence: A Systematic Review 
and Meta-analysis. Eur Urol Focus 2020;6:575-92.

56. Angulo JC, Cruz F, Esquinas C, et al. Treatment of male stress urinary incontinence with the adjustable transobturator male system: Outcomes of a multi-center Iberian study. Neurourol Urodyn 2018;37:1458-66.

57. Doiron RC, Saavedra A, Haines T, et al. Canadian Experience with the Adjustable Transobturator Male System for Post-Prostatectomy Incontinence: A Multicenter Study. J Urol 2019;202:1022-8.

58. Cotugno M, Martens D, Pirola G, et al. Adjustable bulbourethral male sling: Experience after 30 cases of moderate to severe male stress urinary incontinence. Arch Ital Urol Androl 2020;92:7-10.

59. Bochove-Overgaauw DM, Schrier BP. An adjustable sling for the treatment of all degrees of male stress urinary incontinence: retrospective evaluation of efficacy and complications after a minimal followup of 14 months. J Urol 2011;185:1363-8.

60. Loertzer H, Huesch T, Kirschner-Hermanns R, et al. Retropubic vs transobturator Argus adjustable male sling: Results from a multicenter study. Neurourol Urodyn 2020;39:987-93.

61. Cerniauskiene A, Barisiene M, Bakavicius A, et al. Complications after male adjustable suburethral sling implantation. Wideochir Inne Tech Maloinwazyjne 2020;15:496-502.

62. Kretschmer A, Husch T, Thomsen F, et al. Targeting Moderate and Severe Male Stress Urinary Incontinence With Adjustable Male Slings and the Perineal Artificial Urinary Sphincter: Focus on Perioperative Complications and Device Explantations. Int Neurourol J 2017;21:109-15.

63. Sousa-Escandón A, Cabrera J, Mantovani F, et al. Adjustable suburethral sling (male remeex system) in the treatment of male stress urinary incontinence: a multicentric European study. Eur Urol 2007;52:1473-9.

64. Leizour B, Chevrot A, Wagner L, et al. DAdjustable retropubic suburethral sling $\operatorname{Remeex}((\mathrm{R}))$ in the treatment of male stress urinary incontinence: One-year results. Prog Urol 2017;27:238-43.

65. Morey A, Singla N, Chung P, et al. Male Stress Incontinence Grading Scale (MSIGS) for Evaluation of Men with Post-Prostatectomy Incontinence: A Pilot Study. Video J Prosthet Urol 2016;2:64.

66. Viers BR, VanDyke ME, Pagliara TJ, et al. Improving male selectivity and outcomes- A potential role for physical demonstration of stress urinary incontinence severity. Urology Practice 2018;5:458-65.</jrn>
67. Shakir NA, Fuchs JS, McKibben MJ, et al. Refined nomogram incorporating standing cough test improves prediction of male transobturator sling success. Neurourol Urodyn 2018;37:2632-7.

68. Sturm RM, Guralnick ML, Stone AR, et al. Comparison of clinical outcomes between "ideal" and "nonideal" transobturator male sling patients for treatment of postprostatectomy incontinence. Urology 2014;83:1186-8.

69. Grabbert M, Husch T, Kretschmer A, et al. Comparison of adjustable male slings and artificial urinary sphincter in the treatment of male urinary incontinence: a retrospective analysis of patient selection and postoperative continence status. World J Urol 2019;37:1415-20.

70. Tsui JF, Shah MB, Weinberger JM, et al. Pad count is a poor measure of the severity of urinary incontinence. $J$ Urol 2013;190:1787-90.

71. Dylewski DA, Jamison MG, Borawski KM, et al. A statistical comparison of pad numbers versus pad weights in the quantification of urinary incontinence. Neurourol Urodyn 2007;26:3-7.

72. Nitti VW, Mourtzinos A, Brucker BM, et al. Correlation of patient perception of pad use with objective degree of incontinence measured by pad test in men with postprostatectomy incontinence: the SUFU Pad Test Study. J Urol 2014;192:836-42.

73. Yi YA, Keith CG, Graziano CE, et al. Strong correlation between standing cough test and 24-hour pad weights in the evaluation of male stress urinary incontinence. Neurourol Urodyn 2020;39:319-23.

74. Burkhard FC, Lucas MG, Berghmans LC, et al. EAU Guidelines on urinary incontinence. European Association of Urology 2016.

75. Sandhu JS, Breyer B, Comiter C, et al. Incontinence after Prostate Treatment: AUA/SUFU Guideline. J Urol 2019;202:369-78.

76. Bauer RM, Gozzi C, Roosen A, et al. Impact of the 'repositioning test' on postoperative outcome of retroluminar transobturator male sling implantation. Urol Int 2013;90:334-8.

77. Comiter CV. Surgery Insight: surgical management of postprostatectomy incontinence--the artificial urinary sphincter and male sling. Nat Clin Pract Urol 2007;4:615-24.

78. Han JS, Brucker BM, Demirtas A, et al. Treatment of postprostatectomy incontinence with male slings in patients with impaired detrusor contractility on urodynamics and/ or who perform Valsalva voiding. J Urol 2011;186:1370-5. 79. Gomha MA, Boone TB. Voiding patterns in patients 
with post-prostatectomy incontinence: urodynamic and demographic analysis. J Urol 2003;169:1766-9.

80. Comiter CV, Dobberfuhl AD. The artificial urinary sphincter and male sling for postprostatectomy incontinence: Which patient should get which procedure? Investig Clin Urol 2016;57:3-13.

81. Rubin RS, Xavier KR, Rhee E. Virtue Quadratic Male Sling for stress incontinence-surgical guide for placement and delayed revision. Transl Androl Urol 2017;6:666-73.

82. Ziegelmann MJ, Linder BJ, Rivera ME, et al. The impact of prior urethral sling on artificial urinary sphincter outcomes. Can Urol Assoc J 2016;10:405-9.

83. Jimbo M, Alom M, Pfeifer ZD, et al. Prevalence and Predictors of Climacturia and Associated Patient/Partner Bother in Patients With History of Definitive Therapy for Prostate Cancer. J Sex Med 2020;17:1126-32.

84. Salter CA, Bach PV, Miranda E, et al. Bother Associated With Climacturia After Radical Prostatectomy: Prevalence and Predictors. J Sex Med 2020;17:731-6.

85. Nolan J, Kershen R, Staff I, et al. Use of the Urethral Sling to Treat Symptoms of Climacturia in Men After Radical Prostatectomy. J Sex Med 2020;17:1203-6.

86. Christine BS, Bella AJ. Climacturia: an under-adressed sequela of radical prostatectomy, but treatment is only a sling away. Annual Fall Scientific Meeting of the Sexual Medicine Society: J Urol 2016.

87. Andrianne R. The "Mini-Jupette" sling at the time of inflatable penile prosthesis implantation: Adequate treatment for erectile dysfunction with mild incontinence and/or climacturia after radical prostatectomy. Prog Urol 2019;29:456-63.

Cite this article as: Bole R, Hebert KJ, Gottlich HC, Bearrick E, Kohler TS, Viers BR. Narrative review of male urethral sling for post-prostatectomy stress incontinence: sling type, patient selection, and clinical applications. Transl Androl Urol 2021;10(6):2682-2694. doi: 10.21037/tau-20-1459
88. Yafi FA, Andrianne R, Alzweri L, et al. Andrianne MiniJupette Graft at the Time of Inflatable Penile Prosthesis Placement for the Management of Post-Prostatectomy Climacturia and Minimal Urinary Incontinence. J Sex Med 2018;15:789-96.

89. Yafi FA, Brady J, Wilson SK. A new male sling for minimal to moderate incontinence and climacturia. Int J Impot Res 2020. [Epub ahead of print].

90. Towe M, El-Khatib F, Osman M, et al. The use of autologous fascia in the Mini-Jupette graft: two cases. Int J Impot Res 2020;32:140-1.

91. Valenzuela RJ, Ziegelmann MJ, Hillelsohn JH, Preliminary Outcomes of the Male Urethral "Mini-Sling": A Modified Approach to the Andrianne Mini-Jupette Procedure With Penile Prosthesis Placement for Climacturia and Mild Stress Urinary Incontinence. J Sex Med 2019;16:1310-7.

92. Gorbatiy V, Westney OL, Romero C, et al. Outcomes of simultaneous placement of an inflatable penile prosthesis and a male urethral sling through a single perineal incision. J Sex Med 2010;7:832-8.

93. El-Khatib FM, Towe M, Choi J, et al. Management of Climacturia During Inflatable Penile Prosthesis Surgery. Curr Urol Rep 2019;20:16.

94. Kavoussi NL, Hofer MD, Viers BR, et al. Synchronous Ipsilateral High Submuscular Placement of Prosthetic Balloons and Reservoirs. J Sex Med 2017;14:264-8.

95. Sundaram V, Cordon BH, Hofer MD, et al. Is Risk of Artificial Urethral Sphincter Cuff Erosion Higher in Patients with Penile Prosthesis? J Sex Med 2016;13:1432-7. 